reviewed in this journal with the scattered references to various parasitic groups in the present text-book, to realise the inadequacy of the method to which Parker and Haswell are bound by the rigidity of their scheme. The medical and pathogenic significance of the Protozoa and the occurrence of soil-Protozoa deserve more than the passing mention given to them on p. $5 \mathrm{I}$, or than the reference in vol. 2 , p. 6I 7 , "a terrestrial Amœba has been described." The treatment of fresh-water medusæ is also inadequate, and the structure of the common starfish (Asterias) should have been followed by an account of its development now that Dr. Gemmill's account is fully accessible. The account of the Vertebrata is in need of more fresh and vigorous handling, especially from the embryological point of view. For example, to state without comment that a bird has three pancreatic ducts, as is done here, is to miss a fine opportunity of showing the fertilising effect of embryological interpretation. In the chapter on zoological philosophy, the barest indication is given of developmental mechanics and of regeneration, but not of the new point of view raised by American work on Drosophila. The text-book remains, in fact, a useful and well-illustrated account of exemplary anatomy. What students want is a series of small monographs on special subjects. Zoology is too big a subject to be treated adequately in a single work.

\section{Cancer and the Public.}

New Growths and Cancer. By Prof. S. B. Wolbach. (Harvard Health Talks.) Pp. 53. (Cambridge, Mass. : Harvard University Press ; London : Oxford University Press, 1922.) 4s. $6 d$. net.

I $\mathrm{HE}$ lay public nowadays is very much interested in having healthy bodies, and its will to give active co-operative help to the medical profession in achieving this ideal is one of the few features of the new post-war Jerusalem that does not find itself in ruins. Medicine has ceased to be a cult of priests practising some mystery beyond the understanding of common people, and the abandonment of a professional dress means, not so much a recognition that a soft hat and tweeds are more comfortable than a tall hat and black coat, as an open expression that medical men and the lay public are fellow-workers for the common good.

How much may be attained by intelligent and interested lay folk working jointly with doctors has been illustrated lately very clearly by the disappearance of summer diarrhœa and the general decrease in infantile mortality-results, not of the direct application of assured scientific knowledge to practical life, but of the devotion of common-sense men and women in schools for mothers and similar organisations, which followed quickly enough on the conviction that it was shameful that a child should be ailing or should die. It has been said, too, that the problem of venereal diseases was solved the day that "syphilis" appeared in the headlines of a reputable daily paper. It is, indeed, clear that real progress in healthiness is as much a question of laymen as of doctors. William James says somewhere that a good deed can be perfect only if it is well received as well as well done; it is, indeed, to this co-operation of both parties that we must look for further advance.

The knowledge of "medical" matters already enjoyed by the public in general is very much greater than it was even a few years ago. It is obviously a project of high importance that it should be enlarged and extended, and this is the purpose of the "Harvard Health Talks" of which the present small volume is one. It deals with cancer and new growths, and in 53 pages presents a great deal of information. So excellent is the purpose, that it is with some regret that we find the performance disappointing. The book fails in the way that some other books of the same kind have failed. The author has not realised the abyss which separates his training and terminology from those of his audience, and has presented them with an abbreviated version of a set of lectures to professional students rather than a discourse starting from their point of view instead of from his own. With the heartiest appreciation of the intelligence of the inhabitants of Boston and Cambridge, it is difficult to believe that they will get a good start in understanding cancer from "the unit of structure of living matter is the cell" and the rest of the conventional paragraphs of dogmatic biology that form the opening chapter : it is useless as well as unnecessary to ask the educated man in the street to begin a new subject from a point of view and in a terminology which are as Greek or worse to him. The author has evidently never wondered how the man who sits next to him in the street-car would describe the facts if he knew them.

Technically, too, there is room for substantial difference of opinion. Pigmented congenital moles are certainly not universally accepted as examples of " embryonic rests," and the sentences on p. 35 attributing irritation of the bladder to the "embryos" of Bilharzia are misleading. The practical directions with which the lecture concludes are, however, admirable: do not bother about cancer being supposed to be hereditary, avoid irritations, consult a medical man at the first suspicion of anything amiss, and "never select a doctor that you would not accept as a friend."

A. E. B. 